Article

\title{
Smart Libraries
}

\author{
Joachim Schöpfel \\ GERiiCO Laboratory, University of Lille, 59653 Villeneuve d'Ascq, France; joachim.schopfel@univ-lille.fr; \\ Tel.: +33-688-350-147
}

Received: 6 July 2018; Accepted: 27 September 2018; Published: 29 September 2018

\begin{abstract}
Can the smart city provide a new perspective for public and academic libraries? How does the smart city impact the libraries as cultural and scientific assets? And how can libraries contribute to the development of the smart city? An overview of recent library models, like the learning center or the green library, reveals affinities with the concept of the smart city, especially regarding the central role of information and the integration of technology, people, and institutions. From this observation, the paper develops the outline of a new concept of the smart library, which can be described in four dimensions, i.e., smart services, smart people, smart place, and smart governance. However, the smart library concept does not constitute a unique model or project, but a process, a way of how to get things done, that is less linear, less structured, and more creative and innovative. Also, smartness may not be a solution for all library problems.
\end{abstract}

Keywords: smart library; smart city; library marketing; public library; academic library

\section{Challenges}

General models and concepts of the smart city contain several connected components, such as industry and manufacturing, security, healthcare, retail and shopping, energy, waste management, green spaces, transportation, home, and even farming. Cultural and political elements are also part of these models, along with education and university or, on a more abstract level, society as a whole for smart citizenship. Sometimes, they explicitly mention libraries.

Libraries can be described as social and technological-intellectual infrastructures, as essential elements in a "larger network of public services and knowledge institutions of which each library is a part" [1]. Their traditional function is to buy, preserve, and make available books, journals, and other media to a given local, academic, or other community. But, as an information service, they also allow connections between people, and they have the potential to become de facto community centers. They are a physical space, a good place to go and have a good time, welcoming and comfortable, highly accessible, inexpensive or free, with regulars, such as staff [2]. How can they contribute to the smart city?

Libraries are cultural and scientific institutions, with holdings, book stacks, reading rooms, physical learning spaces, as well as virtual hubs of knowledge consumption and production. They play a role in education and information literacy. They are cultural assets, one of those rare places where technology and even productivity meet communal and human values. How does the smart city impact these assets?

Libraries have a problem with advocacy and marketing. For nearly forty years now, people question the future of the library. Some of them even predict the end of the library, unable to cope with the digital age and social change, unsustainable, some kind of vintage of the Gutenberg era; having reached an impasse, they "may disappear like the dinosaurs" [3]. Can the smart city provide a new perspective? Can it add to the library value and its "return on investment"?

Will the technological development contribute to the decline or "significant alteration" of the traditional library? Is this the "end of wisdom" [4]? One thing is sure: the emerging urban environment 
of information technologies and connectivity, mobility, digital nomads, and local community, is highly relevant for the future development of libraries, and libraries must propose innovative solutions if they are to stay in the game. In other words, libraries should interpret the challenge of the smart city as an opportunity, not as a threat.

This is the topic of our paper: how can library management seize the opportunity of the smart city? How can libraries be redefined in this new infrastructural ecology? How does the model of the smart city impact the understanding of libraries? And what would be, in this context, the constituents of a new concept of smart libraries? The paper is based on an overview of recent, relevant literature about new developments in libraries and about models of the smart city. It does not present results from an empirical study, and it does not make recommendations how to implement the different aspects of this new concept. Its only objective is to present the concept of smart libraries to people interested in smart cities and infrastructures, to show the potential value of libraries for the development of smart cities, and to discuss a theoretical framework which may be helpful for the future development of libraries, in specific environments.

\section{Recent Models for the Development of Libraries}

In coping with new social and technological challenges, library and information sciences developed new concepts for the marketing and advocacy of public and academic libraries. There is an abundant corpus of literature, surveys, case studies, etc. about how public and academic libraries move forward and adapt to new technologies, new communities, new user needs and information behaviors, and new public policies. Some of these concepts had impact, and were successful insofar as they shaped the core values, and mission and vision statements of a new generation of libraries. They are also relevant for another reason: main components have affinities with the core features of the smart city. A short overview.

\subsection{Information Commons}

In the context of social media, the concept of efficient communal ownership and control of resources has been applied to libraries, based on the sharing of information in online communities and opposed to profit-dominated markets with their specific forms of enclosure [5].

Commons are resources or facilities shared by communities of producers or consumers. Their basic ideas are collaboration, interaction, networking, shared governance, and non-profit business models. The value of the resources is determined by participation and sharing, not by rarity. Sharing of information is part of the core values of libraries: "Librarians and other information workers' interest is to provide the best possible access for library users to information and ideas in any media or format ( ... ). They promote the principles of open access, open source, and open licenses" [6].

In library sciences, the term "information commons" has been used to describe specific services and tools, e.g., library-based open access journals and free available digital libraries, as well as the underlying core values and organizing principles, like openness, unrestricted access and non-discrimination, non-profit, and so on. Libraries, as a public institution, build on the participation of local or academic communities, and on the protection of intellectual freedom, i.e., freedom of expression and information.

Information commons have been (and still are) a powerful concept for the marketing and promotion of public and academic libraries, for nearly 15 years now. In the United Kingdom, public libraries have been transformed into idea stores with several learning, informative, entertaining, and cultural opportunities [7]. Regarding smart cities, two elements make the link: the community, and the shared resources and facilities.

\subsection{Learning Centres}

Other models have emerged to increase the academic libraries' attractiveness and performance on campus, like learning commons, media commons and, above all, learning centres. These models shift the 
library focus away from holdings and silent reading, to modular learning spaces, smart technologies, and "great good place" features [2], which put students at the heart of the library. The focus is on learning. Pedagogy has become a major driver for library design that should facilitate learning processes centred on autonomy, self-monitoring, and personal knowledge management. Some of them integrate elements from innovation and co-working spaces [8].

Design and architecture play a major role. What should an academic library do with its space? What kind of building, physical environment, and technical equipment fits best to support and improve the quality of student learning [9]?

Again, sharing resources and facilities are essential components of the concept. Other interesting aspects are the attention paid to usage, experience, learning and cognition, and the role of social and mobile technologies.

\subsection{Green Libraries}

How can the library contribute to the protection of the natural environment? Compared to power plants, chemical industry or road transport, libraries are relatively clean, and their carbon footprint is smaller than a coal plant or a blast furnace. Yet, libraries consume energy and water, buy chemicals, and produce waste. As any other service, they are concerned by questions of environment and pollution. The concept of the green library tries to provide an answer to the challenge of ecology [10].

The model of the green library offers the framework for a large range of actions in favor of waste reduction, recycling, saving energy, and so on. Some actions are linked to new buildings or important renovations (green roof); others can be implemented at any time (use of energy-efficient light bulbs, recycling of paper). Other levels of action are education, awareness raising and advocacy, and access to specialized information. Additionally, the model provides checklists and standards for the evaluation of the libraries' ecological impact [11].

The model of green libraries is not limited to academic libraries, but applicable to all kinds of libraries. Buildings and "clean" technologies and equipment play a central role, but they are embedded in training, education, and everyday environmental actions. Also, the model introduces the concept of sustainability into the field of library sciences.

\subsection{Global Library}

Insofar as the green library model puts the focus on environmental issues, it remains a somewhat reducing concept, at least as long as it does not include the other dimensions of sustainable development, as defined by the UN (Agenda 21) and other international bodies. Libraries are cultural institutions, supporting education and research, but they are more than that-they are also part of the local community, sometimes as a kind of social agency; they are, like any other service, potential contributors to the sustainable development of society and mankind, and they should be evaluated within this framework. This means that library management and marketing should develop a holistic approach ("global library") and adapt the principles of corporate and organizational social responsibility to the specific environment of public and academic libraries [12].

\subsection{Convergent Features}

Information commons, learning centres, and green and global libraries, represent different responses to the same technological and societal challenges. Their concepts provide frameworks for the marketing and management of libraries. They share the conviction that the present context offers sufficient opportunities for the future development of libraries, and that the libraries, as "opportunity institutions" [1], possess enough potential and flexibility to adapt and survive.

The strength of these models can be summarized by seven convergent features:

1. The epistemic framing as a cultural infrastructure in an ecosystem of knowledge institutions. 
2. The strong connection with the community and the attention paid to the users' needs, behaviors, experiences, and information literacy.

3. The attention paid to the social and societal impact of the institution, with new social functions (social responsibility).

4. The care for sustainability and environmental issues as criteria for strategic choices.

5. The principles of resource sharing, collaboration, networking and openness.

6. The importance of innovative technologies.

7. The vital role of the building.

These convergent features create a new and original conceptual environment for the development of library services, organizational structures, and functioning. Also, in comparison with the recent evolution of urbanism, there are obvious affinities with the concept of the smart city. Thus the smart city may offer a new, inclusive approach to library science.

\section{Affinities with the Smart City}

The smart city has been described as an "urban labeling" phenomenon, a "fuzzy concept", rather than a consistent framing or one-size-fits-all definition [13]. In the same way, other authors have characterized the smart city as an ambiguous, generic, and optimistic concept for the "city of the future", intended chiefly as an "efficient, technologically advanced, green and socially inclusive city" [14].

Several meanings and connotations have been linked to the term of "smart", e.g., efficient, sustainable, equitable, livable, instrumented, interconnected, intelligent city: "The use of Smart Computing technologies to make the critical infrastructure components and services of a city (...) more intelligent, interconnected, and efficient (... ) A city that gives inspiration, shares cultures, knowledge, and life, a city that motivates its inhabitants to create and flourish in their own lives" [13].

The relevant point for the development of public and academic libraries is not this assemblage of "pre-existing urban imaginaries" [14]. Two other aspects are of interest, i.e. the focus on information and the multidimensionality of the concept.

\subsection{The Focus on Information}

Smart cities have been described as a "ubiquitous digital eco-system", made by a myriad of information-centric services willing to interact with each other [15], as an environment for information sharing, collaboration, interoperability, and seamless experiences. Technology makes the city intelligent; people ("smart community") create knowledge by means of information and communication technologies that "strengthen the freedom of speech and the accessibility to public information and services" [13]. Libraries are part of the informational ecosystem; they are, in themselves, technological and intellectual infrastructures providing access to information, collecting data, producing information and knowledge, and creating cultural and scientific value for the community. The affinity with the 3 I's of the smart city, i.e., instrumentation (the capture and integration of live real-world data through the use of data-acquisition systems, including the web and social networks), interconnectedness (integration and interconnection across multiple processes and systems, including unstructured or massive information, i.e., big data), and intelligence (complex analysis of this interconnected information to provide new insights that drive decisions and actions that improve outcomes and change the end-user experience or ecosystem) [16], is obvious.

\subsection{A Multidimensional Approach}

Even if digital infrastructures and innovative technologies are preponderant components of the smart city, the technological dimension of the concept is embedded in a larger context, i.e., the human and the institutional dimensions. The smart city is more than new information and communication technology (ICT) and connected objects. It builds on creativity, intellectual and social capital, "intangible assets" [17], and it needs governance, policy and regulations, i.e., conscious decisions "to use 
that technology to transform life and work (...) in significant and positive ways" [13]. Technology is the core dimension, but technology alone does not make the smart city. As a psychologist would say, the people make the city, and the smart people make the smart city-the people, and the society. This is another affinity with libraries and their cultural, societal, and human dimensions.

\subsection{Towards a New Model}

Both aspects, the focus on information and the multidimensionality, make the concept of the smart city attractive for the development of libraries. Since 2013, a couple of studies, especially from China and India, have introduced the concept of the smart library (see for instance [18]). However, the term was used in a non-consistent way and centered on technology and related work skills. Like the (interesting) Smart Libraries Newsletter published by the American Library Association [19], they lay the main focus on radio-frequency identification (RFID), the Internet of Things and connected objects, mobile devices, infrastructures, and Big Data. Less attention is paid to the social and human dimensions, to the "soft" domains like living, government, economy, and people [17].

Yet, it is above all, the human dimension of the smart city, i.e., the role and development of creativity, education, learning, and knowledge, that makes the concept attractive for libraries (Figure 1). An inclusive and multidimensional concept of a smart library was presented at the European Conference on Information Literacy (ECIL) in 2015, where Adam Sofronijevic and his colleagues from the University of Belgrade described the transformation of public library services into an "information literacy hub" for smart people, in a "city that has changed and become smart and more sustainable" [20]. Another study highlights the provision of explicit knowledge via digital libraries as an indicator for a city's "informationality"; the digital libraries offer an "additional universal service for knowledge" on the city level [21]. The following section will give some complementary insights into this new concept and explore its potential as a useful label for the development of public and academic libraries.

One may understand smart libraries as synonymous with modern libraries. This is right insofar as smart libraries are part of new, modern library concepts; libraries are moving forward, and they are adapting to new societal and technological opportunities and threats. This is wrong if the term "modern" limits the meaning of smart to new and modern technology, without the other social and human dimensions, and without, above all, the interconnection with the urban environment of smart cities. Implementing RFID does not make a library smart; it can be part of its smartness if it is embedded in the context of a smart city and as an element of a multidimensional framework including aspects related to the community, to the building and the governance. Insofar, the smart library concept can be understood as an approach that introduces consistency into several recent, "modern" library developments, in the urban environment of smart cities.

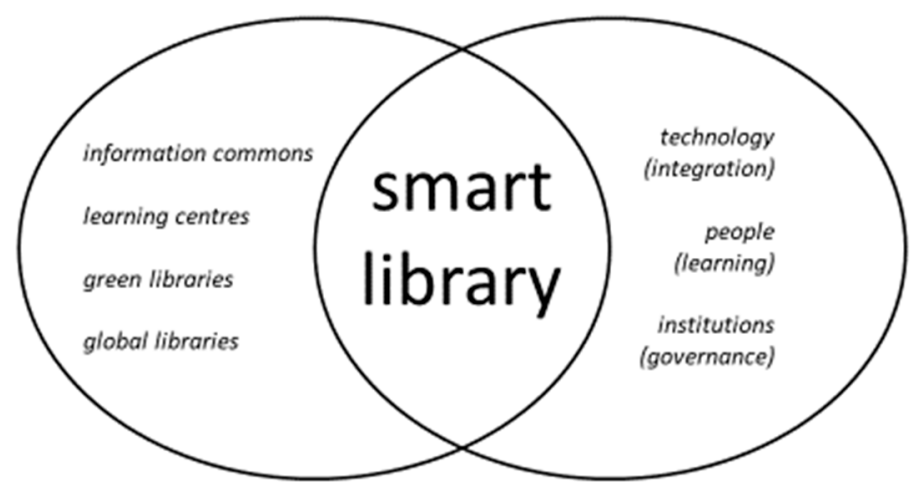

Figure 1. The smart library at the interface between library concepts and the smart city.

\section{Dimensions of Smart Libraries}

Smart city initiatives are a mix of hard (natural resources and energy, transport and mobility, buildings) and soft (living, government, economy, and people) domains. Giffinger et al., for instance, 
ranked 70 medium-sized European cities in six main innovation axes, i.e., smart economy, smart mobility, smart environment, smart people, smart living, and smart governance [22]. This comprehensive approach integrates "smart features" from technology, people, and institutions.

In fact, however, hard and soft domains are often separated, and more attention is paid to the hard domains, especially transport and natural resources, than to government and people. "Many municipalities and their technology vendors mainly focus on technology, not on people" [17].

Such a "smart strategy" reflects a double error. Not only does it neglect the fundamental nature of smartness, i.e., "smartness is centered on a user perspective" [13], but it also virtually marginalizes soft domains, which are important and relevant for citizens and their quality of living.

What does this mean for the library? As an institution of culture and education, as an information common, as well as a third place, a library appears to have more affinity with the soft domains, with people and with living. The smart city, in its role as "learning city" or "knowledge city", is designed to encourage the nurturing of knowledge and innovation [13]. Adapting the well-known definition by Giffinger et al. [22], one could say that a smart library is well-performing in a forwardlooking way, as an information-hub, providing access to information and improving information literacy; the concept refers to the search and identification of intelligent solutions which allow modern libraries to enhance the quality of the services.

The concept of the smart library has a double character: it allows the consistent description of some particular developments and realizations of public and academic libraries in urban settings and on scientific campuses. It can also contribute to a new and dynamic vision of the libraries of tomorrow, helpful to define objectives and strategies how to get there and helpful, too, for library marketing and advocacy.

For the description and development of smart libraries, it can be useful to distinguish four dimensions, i.e., smart services, smart people, smart place, and smart governance (Figure 2).

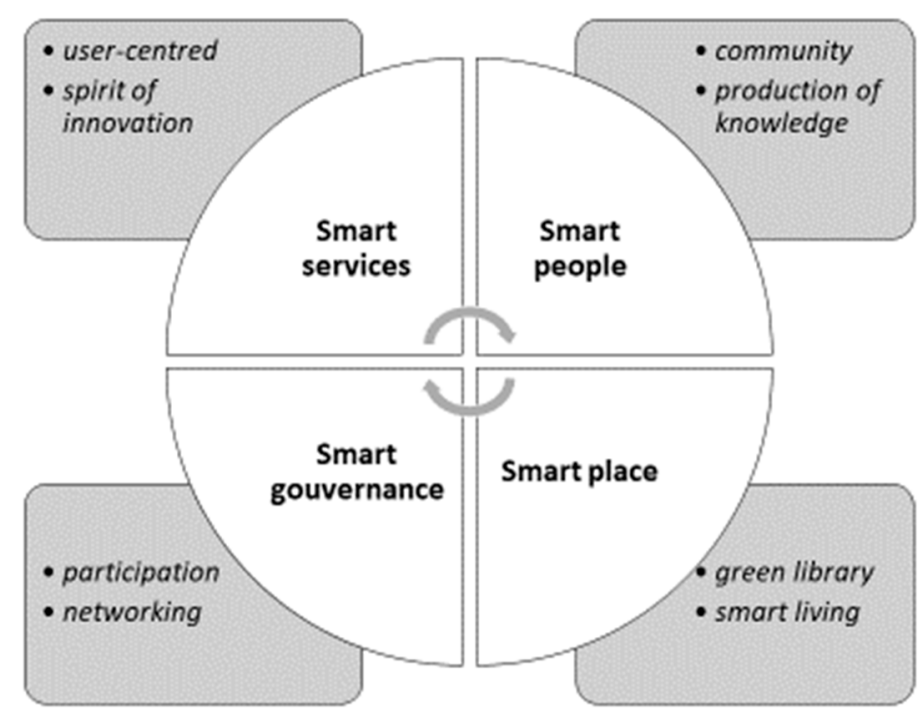

Figure 2. Four dimensions of the smart library.

\subsection{Smart Services}

The first dimension can be described as the application of the "spirit of innovation" of smart cities to the development of modern library services. Papers on smart libraries often focus on this dimension, and present technological innovation as smart services, such as RFID, mobile and wireless access, remote assistance, semantic web, artificial intelligence, the Internet of Things, machine translation, voice and image recognition, natural language processing, augmented reality for delivering new experiences in enjoying cultural heritage etc. 
Some papers describe smart library services as library-based ICT platforms, for document search, information retrieval, collaborative collection building etc. Another characteristic of smart library services is the interoperability and interconnection with other information services. A smart library is an information hub connected with other libraries and urban services in a larger informational ecosystem.

However, these innovative tools and services are smart only insofar as they are user-friendly and user-centered. Smartness means that the development of new tools and services is based on the assessment of real usage. The user defines the library. "Smart is more user-friendly than intelligent" [13]. Instead of trying to adapt the user to existing library services, smart libraries are required to adapt themselves to the user needs.

The assessment of real usage can include mobile crowd sensing in order to support smart mobility, usage of library space, and access to library facilities [23], agile management, UX design, and personalized information discovery based on recommendations (algorithms).

\subsection{Smart People}

Smart libraries are made for and with smart people. Not only are smart library services user-friendly and user-centered, they are also grounded in the vision or assumption of the smart library user as an active (co)-producer of knowledge and not as a passive consumer of information.

The citizens of smart cities are described in terms of flexibility, creativity, tolerance, cosmopolitanism, empowerment, and participation in public life. Their level of qualification is valued as human and social capital (assets), and the services are required to contribute to the development of these characteristics and skills.

In the specific environment of libraries, we can translate this concept of smart people as follows, on two levels:

Smart community: in fact, the concept of smart people does not only include the smart citizen, user of smart library services, but also the staff of the library, their skills, and job development. The library staff is part of the smart people, for instance, when it comes to the production and analysis of information and data (data librarian) or to the control of discovery tools.

Production of knowledge: the library user is a producer of knowledge, or co-producer alongside with other users and/or the staff. Creation, enrichment, sharing of information and knowledge, are other terms that describe the vision of the smart library user's role and action. This vision is converging with the conceptualization of the library as a "platform of the commons", where knowledge is produced by and with citizens [24].

Tomorrow, perhaps, the library will be more than ever a place of life, encounter, emancipation, and artistic and scientific education, with space for reading, music, theater, exhibitions, cafeterias, fab labs, etc. [25]. Tomorrow the main library function will be mediation and more, e.g., facilitation, assistance, and co-production.

However, there may be one fundamental issue in need of particular attention, i.e., the potential conflict between the goals and usage of smart technology and the traditional values associated with libraries. Smart cities have been criticized as prone to mass surveillance and privacy invasion, at risk of reducing citizens' liberty [26]. This is not compliant with the respect of personal privacy, the protection of personal data and the confidentiality of library transactions as described by the Code of Ethics of the International Federation of Library Associations and Institutions (IFLA). This potential conflict between library ethics, institutional, local or national policies, and law, is not new; there has been substantial debate on the topic, and there are solutions how to deal with it. But, it must be addressed in the particular environment of smart libraries, in order to avoid misunderstanding, fear, and rejection, not only by the library staff but, above all, in the user community itself. Smart people are generally aware of the risk of surveillance and lost privacy, and they will not accept abusively reduced privacy and confidentiality in "their" library, which always has been a protected place of individual liberty. 


\subsection{Smart Place}

The third dimension refers to the library as a building and as a place. In a general manner, this dimension can be described as "smart environment" and environmental monitoring. In fact, we can distinguish two different aspects.

The first aspect is ecology, and similar to the concept of the green library mentioned before $[10,11]$. It covers, for instance, compliance with sustainable building rating systems, waste management, attractiveness of natural conditions, lack of pollution, and sustainable management of resources, etc. One part is sustainable architecture and engineering. The other is ecological functioning and management. Together, they represent the libraries' contribution to sustainable development and biodiversity.

The second aspect can be described as smart living related to buildings and means, for instance, building monitoring and control, monitoring of electrical devices, personal safety, and a healthy environment for the staff, as well as for the public. This aspect includes innovations that contribute to improving the quality of life and attractiveness of the library as a building and as a place. We can see similarities with the "hard" attributes of the library as a third place, with its architectural design, functioning etc.

This third dimension, "smart place", combines innovative qualities from the green library and the "third place library", and describes the transformation of the traditional library building and functioning into a smart place that contributes as much to the sustainable development as to the smartness of the city.

\subsection{Smart Governance}

The last dimension of the smart library is institutional and political. It includes all library features that correspond to the concept of "smart governance" in the city, which encapsulate, for instance, collaboration, cooperation, partnership, citizen engagement, and participation [27]. In the heart of the smart governance is the community, which understands the potential of information technology for the development of the library, as a means of reinvesting libraries for a new ecosystem. "Institutional preparation and community governance are essential to the success of smart community cities" [13]. Again, we can distinguish two aspects.

Smart management: smart library management can include several initiatives, like increasing transparency of the administration and management system, user participation in decision-making processes, automatic and optimized administration procedures, real-time analysis of big data on library usage to improve the quality of library strategies and decision-making etc. The library user becomes stakeholder of the library and takes part in the library management and administration.

Smart networking: the second aspect of smart governance is networking or, in other words, the library openness and embeddedness in its social and cultural environment. Also, decisions should be taken collectively, not as an isolated institution but as an element in the larger ecosystem of other libraries, information hubs, and third places.

The keyword of smart governance is collective intelligence, based on shared responsibilities between the library staff, the library community, and other institutions. "Collective coherence will be a critical success factor in gaining future traction in public policy" [28]. Smart governance is one way to increase social coherence. The public library can contribute in many ways to the local policy, with contributions to culture and education, filling the gap of information literacy and improving the access to relevant information and social services [29].

Who will fund smart libraries, and who will benefit from this investment? The concept of smart libraries applies to public and academic libraries and, so, the potential funders of smart library developments will be the actual funders, e.g., local authorities, universities, academic funding agencies, foundations, etc. As said before, the concept of smart libraries is precisely an argument to justify new library investment, in a time where public investment has become a rarer resource. Also, the context of smart cities may be helpful to identify other potential funding sources, such as public-private partnerships for specific services or technologies. The second question-who will 
benefit from smartness-seems simpler than it actually is. At first sight, the answer is: of course the user community will be the first and principal beneficiary, insofar the new service development is centered on its needs and practices. However, there are at least two other benefits-for the local authority or academic institution, insofar as smart libraries will improve their global smart service quality in the field of information and knowledge; and, for the ICT industry, as the main provider of new technologies, compliant with the concept of smartness.

What about the library staff? Where new technologies have already be implemented, the impact on library job skills and profiles is paradoxical and contradictory. Some profiles will need more skills (not only ICT but also management, communication, and social skills) while other profiles will disappear or be impoverished. Here is not the place to anticipate job developments or to make recommendations, but the experience with ICT implementation in the libraries during the last decades (library systems and databases, personal computers, internet, and the web, social media etc.) are there to remind that each significant change is a source of fear, and needs a suitable human resource policy. As every new paradigm, smartness bears risks. Smart governance, such as described above, is one way (but not a guarantee) to anticipate, prevent, and deal with risks appropriately.

\section{Conclusions}

Can the smart city provide a new perspective for public and academic libraries? How does the smart city impact the libraries as cultural and scientific assets? And how can libraries contribute to the development of the smart city?

The recent models of public and academic libraries, such as the learning center or the green library, show several affinities with the concept of the smart city, especially regarding the central role of information and the integration of technology, people, and institutions.

From this observation, we developed the outline of a new concept of the smart library which can be described on four dimensions, i.e., smart services, smart people, smart place, and smart governance. As for the smart city, the concept of the smart library remains somehow "fuzzy", open, and dynamic. The smart library concept does not constitute a unique model or project, but a process, a way of how to get things done, that is less linear, less structured, and more creative and innovative.

Even if it appears too early to forecast financial issues of the implementation of smart services, the concept will probably increase library value in two different ways: insofar as smart libraries will develop new services or take over other community functions of information access and knowledge production, it will increase the return of public investment for the university or local authority. Insofar as it improves the quality of traditional library functions and satisfies more and new users' information needs, it will also develop the "virtual" cultural and social library assets, as measured by methods like contingent valuation $[30,31]$.

Also, the concept may not apply to all libraries. Smartness may not be a solution for all library problems. However, the concept of the smart city offers, at least for some libraries, an opportunity to prove their social value. Not all libraries will (should) become smart. A library can be modern, improve its service quality, develop new services, and implement new information technology without being (or claiming to be) smart. For instance, for libraries in rural environments, smartness is surely not on the top of the agenda, because of the lack of urban context. But, some libraries must adapt to emerging smart environments, in the city or on the campus, where smartness becomes a topic. Smart urbanism creates a new situation to which libraries have to respond. Our paper tries to illustrate some affinities with recent library developments. It tries also to provide some elements how library marketing and advocacy can seize the opportunities the smart city offers, for further development of library services. Just being "modern" in a world that claims to be "smart" and that requires "smartness" is not enough for further funding and investment.

In a world where information has become ubiquitous, libraries have to reinvent their role and function in the new ecosystem. They do not enjoy an exclusive monopoly on information access and management and some of their informational functions and roles may and will be externalized and 
played by other institutions and structures. The future library may be very different from what we see now. Perhaps "a new name is needed for buildings that contain many of the essential functions of a ( . . ) library but which have a different character of emphasis" [32]. Our idea is that, in the urban environment and on the university campus, "smart library" may be one major candidate for this new name. Traditional marketing says, without customers, no service. Setting this rule on its feet, we would rather say that without smart services, no smart people. The smart library is an option to stay in the game and defend the fundamental library assets as a "civic landmark" [1] in the upcoming smart society.

Funding: This research received no external funding.

Acknowledgments: I would like to thank Chérifa Boukacem-Zeghmouri (Lyon), Claude Poissenot (Nancy), Isam Shahrour (Lille) and Isabelle Westeel (Grenoble) for helpful discussions on smart cities and smart libraries.

Conflicts of Interest: The author declares no conflict of interest.

\section{References}

1. Mattern, S. Library as Infrastructure. Places J. 2014. [CrossRef]

2. Oldenburg, R. The Great Good Place: Cafés, Coffee Shops, Community Centers, Beauty Parlors, General Stores, Bars, Hangouts, and How They Get You through the Day; Paragon House: New York, NY, USA, 1989.

3. Thompson, J. The end of libraries. Electron. Libr. 1983, 1, 245-255. [CrossRef]

4. Evans, W.; Baker, D. (Eds.) The End of Wisdom? The Future of Libraries in a Digital Age; Chandos: Oxford, UK, 2017.

5. Kranich, N.; Schement, J.R. Information commons. Annu. Rev. Inf. Sci. Technol. 2008, 42, 547-591. [CrossRef]

6. IFLA Code of Ethics for Librarians and Other Information Workers. Available online: https:/ / www.ifla.org/ faife/professional-codes-of-ethics-for-librarians (accessed on 14 June 2018).

7. Galluzzi, A. Cities as long tails of the physical world: A challenge for public libraries. Libr. Manag. 2011, 32, 319-335. [CrossRef]

8. Schöpfel, J.; Roche, J.; Hubert, G. Co-working and Innovation. New Concepts for Academic Libraries and Learning Centres. New Libr. World 2015, 116, 67-78. [CrossRef]

9. Watson, L. (Ed.) Better Library and Learning Space: Projects, Trends and Ideas; Facet: London, UK, 2013; ISBN 9781856047630.

10. Hauke, P.; Latimer, K.; Werner, K.U. (Eds.) The Green Library: The Challenge of Environment Sustainability. IFLA Publications 161; De Gruyter: München, Germany, 2013; ISBN 978-3-11-030972-0.

11. McBane Mulford, S.; Himmel, N.A. How Green Is My Library? Libraries Unlimited: Santa Barbara, CA, USA, 2010; ISBN 9781591587804.

12. Schöpfel, J. Strategic Library Management with the United Nation's Agenda 21. In Advances in Librarianship, Volume 38-Management and Leadership Innovations; Woodsworth, A., Penniman, W.D., Eds.; Emerald: Bingley, UK, 2014; pp. 269-286. ISBN 978-1-78350-469-5.

13. Nam, T.; Pardo, T.A. Conceptualizing smart city with dimensions of technology, people, and institutions. In Proceedings of the 12th Annual International Digital Government Research Conference: Digital Government Innovation in Challenging Times, College Park, MD, USA, 12-15 June 2011. [CrossRef]

14. Vanolo, A. Smartmentality: The Smart City as Disciplinary Strategy. Urban Stud. 2014, 51, 883-898. [CrossRef]

15. Piro, G.; Cianci, I.; Grieco, L.A.; Boggia, G.; Camarda, P. Information centric services in Smart Cities. J. Syst. Softw. 2014, 88, 169-188. [CrossRef]

16. Harrison, C.; Eckman, B.; Hamilton, R.; Hartswick, P.; Kalagnanam, J.; Paraszczak, J.; Williams, P. Foundations for Smarter Cities. IBM J. Res. Dev. 2010, 54, 1-16. [CrossRef]

17. Neirotti, P.; De Marco, A.; Cagliano, A.C.; Mangano, G.; Scorrano, F. Current trends in Smart City initiatives: Some stylised facts. Cities 2014, 38, 25-36. [CrossRef]

18. Aithal, P.S. Smart Library Model for Future Generations. Int. J. Eng. Res. Mod. Educ. 2016, 1, 693-703. Available online: https:/ / ssrn.com/abstract=2822978 (accessed on 4 July 2018).

19. Smart Libraries Newsletter. Available online: https://journals.ala.org/index.php/sln/index (accessed on 4 July 2018). 
20. Jerkov, A.; Sofronijevic, A.; Stanisic, D.K. Smart and Sustainable Library: Information Literacy Hub of a New City. In Proceedings of the European Conference on Information Literacy ECIL, Tallinn, Estonia, 19-22 October 2015.

21. Stock, W.G. Informational cities: Analysis and construction of cities in the knowledge society. J. Am. Soc. Inf. Sci. Technol. 2011, 62, 963-986. [CrossRef]

22. Giffinger, R.; Fertner, C.; Kramar, H.; Kalasek, R.; Pichler-Milanovic, N.; Meijers, N. Smart Cities-Ranking of European Medium-Sized Cities; Centre of Regional Science (SRF), Vienna University of Technology: Vienna, Austria, 2007; Available online: http://www.smart-cities.eu/download/smart_cities_final_report.pdf (accessed on 14 June 2018).

23. Stojanovic, D.; Predic, B.; Stojanovic, N. Mobile crowd sensing for smart urban mobility. In European Handbook of Crowdsourced Geographic Information; Capineri, C., Haklay, M., Huang, H., Antoniou, V., Kettunen, J., Ostermann, F., Purves, R., Eds.; Ubiquity Press: London, UK, 2016; pp. 371-382. ISBN 978-1909188792.

24. Desfarges, P. La bibliothèque distribuée: Fabriquer ensemble un territoire des communs de la connaissance. In Communs du Savoir et Bibliothèques; Dujol, L., Ed.; Electre-Editions du Cercle de la Librairie: Paris, France, 2017; pp. 171-183. ISBN 978-2-7654-1530-5.

25. Tobelem, J.M. Comment garantir la pérennité des bibliothèques? In Évaluer la Bibliothèque par les Mesures d'Impacts; Touitou, C., Ed.; Presses de l'Enssib: Villeurbanne, France, 2016; pp. 17-24. ISBN 979-10-91281-76-8.

26. Froomkin, A.M. Regulating Mass Surveillance as Privacy Pollution: Learning from Environmental Impact Statements. Ill. Law Rev. 2015, 1713-1790. Available online: https:/ /illinoislawreview.org/print/volume2015-issue-5/regulating-mass-surveillance-as-privacy-pollution-learning-from-environmental-impactstatements / (accessed on 4 July 2018).

27. Coe, A.; Paquet, G.; Roy, J. E-Governance and Smart Communities. Soc. Sci. Comput. Rev. 2001, 19, 80-93. [CrossRef]

28. Batt, C. Library 2050. In Libraries and Society: Role, Responsibility and Future in an Age of Change; Baker, D., Evans, W., Eds.; Chandos: Oxford, UK, 2011; pp. 399-416. ISBN 9781843341314.

29. The Lyon Declaration on Access to Information and Development. Available online: https://www. lyondeclaration.org (accessed on 14 June 2018).

30. McIntosh, C.R. Library return on investment: Defending the contingent valuation method for public benefits estimation. Libr. Inf. Sci. Res. 2013, 35, 117-126. [CrossRef]

31. Hajek, P.; Stejskal, J. Modelling public library value using the contingent valuation method: The case of the Municipal Library of Prague. J. Librariansh. Inf. Sci. 2014, 47, 43-55. [CrossRef]

32. Oyston, E. The modern academic library. In Libraries and Society: Role, Responsibility and Future in an Age of Change; Baker, D., Evans, W., Eds.; Chandos: Oxford, UK, 2011; pp. 165-178. ISBN 9781843341314. 